\title{
Examining Teachers’ Decisions to Pursue Graduate Programs in Administration or Curriculum
}

\author{
Teresa M. Starrett \\ Department of Teacher Education, Texas Woman's University \\ P.O. Box 425769, Denton, TX, USA 76204-5769 \\ Tel: 1-940-898-2764Ｅ-mail: tstarrett@twu.edu
}

Pat J. Casey

Department of Educational Leadership and Policy Studies, University of Texas at Arlington Box 19575, 701 Planetarium Place, Arlington, TX, USA 76019-0575

Tel: 1-512-775-4104 E-mail: pjcasey@uta.edu

\author{
Karen Dunlap \\ Department of Teacher Education, Texas Woman’s University \\ P.O. Box 425769, Denton, TX, USA 76204-5769 \\ Tel: 1-940-898-2764Ｅ-mail: kdunlap@twu.edu
}

Received: Nov. 1, 2012 Accepted: November 28, 2012 Published: February 1, 2013

doi:10.5296/jse.v3i1.2609 URL: http://dx.doi.org/10.5296/jse.v3i1.2609

\begin{abstract}
This study examines several factors that may have motivated teachers to either pursue a Master's degree in Curriculum and Instruction (C\&I) or one in educational administration. From a total of 120 applicants' submitted letters of intent collected during 2012, four areas were qualitatively investigated: reasons for choosing the particular Master's program, goals for degree attainment, personal/professional qualities possessed and perspectives about education as a profession. Letters were de-identified and examined for themes. Overwhelmingly, teachers pursing the curriculum degree cited additional knowledge needed to affect change in the classroom while those seeking the administration degree cited a desire
\end{abstract}


to educate themselves in order to have a widespread impact as primary reasons for their choice of degree.

Keywords: Master’s degree, Teacher leader, Administration 


\section{Examining teachers' decisions to pursue graduate programs in administration or curriculum}

This study examines factors influencing teachers' decisions to pursue a Master's degree in education with either educational administration or curriculum/instruction (C\&I) as the main focus. Within each specific area, be it C\&I or educational administration, teachers' career aspirations were quite different - particularly regarding the impending assumption of a leadership position. Using written statements of intent from two groups of teachers seeking different graduate degrees, this study explores teacher degree candidates' perspectives regarding the reasons behind the direction they chose to advance their careers.

For a teacher, the decision to pursue a graduate degree and possibly advance to a new position in the school or school district involves a number of personal, professional and social considerations. Development of professional identity associated with career change or advancement may involve a variety of factors such as opportunities to try out roles and responsibilities associated with the new job (Marshall \& Kasten, 1994) or observations of role models (Ibarra, 1999). When considering taking on an administrative position, teachers are known to experiment with leadership on campus by, for example, chairing or facilitating committees or groups (Marshall \& Kasten, 1994). Teachers may choose campus leadership based on "a tap on the shoulder... When the principal or superintendent says to a teacher, 'You know you'd make a good administrator'..." this is "a rather direct signal that this person should consider an administrative career (Marshall \& Kasten, 1994, p. 6)." According to Phelps (2008), before teachers can adopt leadership as a possibility, they must understand its meaning. In this study, all participants were considered leaders; however, their leadership looked different. Danielson (2006) states that teacher leaders are not typically appointed to traditional campus leadership positions such as principal or assistant principal positions. However, they work closely with and complement the appointed, administrative leaders. It is important to note without teacher leaders, school leaders would not be successful.

The move to administration has complex social ramifications that are often manifested in professional norms and school culture. The move to administration may be jokingly referred to as a move to the dark side or becoming one of them rather than one of us. Concurrently, Donaldson (2007) asserts teachers are often resistant to the idea of traditional school leadership because they prefer instead to effect change on the classroom level through relationship building with colleagues and students. When teachers move to administration, they leave their teacher group - surrender their teacher affiliations, attachments or loyalties and they are compelled to establish new relationships with their colleagues (Armstrong, 2009). Similarly, Schmerler (2009) posits that

"There is a fundamentally egalitarian ethos in the teaching profession. Those who would step forward to offer advice to their peers, or promote innovative ideas, or speak up on behalf of their colleagues are, as often as not, regarded with suspicion or resentment...Teacher leaders commonly report feeling trapped ... between the teachers whom they attempt to influence and represent and the administrators who count on them to do work that the administrators are, for various reasons, unable to do themselves — while being trusted fully by neither.” (n.p.) 
Other authors have isolated various factors involved in teachers' reasons for entering administration or for choosing not to (Armstrong, 2009; Howley et. al. 2005; Marshall \& Kasten, 1994). Teachers also observe that people in administrative positions are more involved with jobs like managerial tasks, politics, budgets, and media while much less involved with teaching children. Thus, the price for prestige and increased recognition is often perceived to be paid with lost relationships and sacrificial limitations placed on involvement in the process of teaching and learning (Marshall \& Kasten, 1994). The potential loss of valuable relationships inherent in the rise to a principal or assistant principal position intensifies existing tension because a principals' work is embedded in a complex web of relationships and that the most effective principals are those who value relationships most (Donaldson et al., 2009).

While school administrators traditionally have more status and higher pay than teachers, teachers see that with a higher status come increased pressures and very different job responsibilities. Typically, teachers observe school administrators working long hours that steal personal time and attention away from the needs of their families. Such demanding conditions often affect teachers' decisions to choose a career in campus administration (Marshall \& Kasten, 1994). Hence, teachers who are masters of curriculum and instruction often choose to serve in educational leadership roles albeit not as a campus principal or assistant principal. As school leadership becomes increasingly complex, campus administrators and trained teacher leaders may create dynamic school organizations through symbiotic relationships sustained via distributed leadership practices (Lieberman \& Miller, 2004).

\section{Theoretical Perspective}

The purpose of this study was to explore factors influencing teachers' decisions to pursue a graduate degree in either educational administration or curriculum. The process of advancing one's career involves reflection encompassing both internal and external considerations (Armstrong, 2009) and, we argue, deliberation of personal and social paradigms as well. As such, we employed Ibarra's (1999) theoretical construct of the provisional self to identify participant career aspiration perspectives at pivotal career decision-making points.

First, we looked at the individual letters of intent for statements targeting professional identity development as conceptualized by Ibarra (1999). Ibarra (1999) posits that an individual's professional identity, especially in times of career transition, is influenced by a combination of factors. Situational factors such as socialization practices and available role models coupled with individual factors like abilities and experiences contribute to a person's conceptual models of what he/she might be, i.e., a repertoire of "possible selves with skills, attitudes, styles, and routines corresponding to possible selves in the new role (p. 787).” Ibarra's construct of possible or provisional selves, suggests that teachers seeking admission to a program in educational administration that is designed to qualify them to move into a leadership role as principal, head of school, or other school administrator would report different situational and/or individual contributing factors from the teachers who did not want to be school administrators and expressed other career aspirations. 


\section{Methodology}

This study looked at letters of intent from two groups of teachers seeking Master's degrees. This study sought to understand the teachers' decisions to seek a Master's degree in educational administration (Ed.Ad.) or a Master's degree in curriculum and instruction (C\&I). To better understand the personal, professional and social factors at play in an individual's decision to pursue a graduate degree and, moreover, seek a leadership position, we used letters of intent from two groups of degree applicants. The two degree programs were housed in the same college of education at a public university in the southwestern United States. Both programs led to a Master of Education (M.Ed.) degree, were designed for individuals who were licensed teachers, and both required 36 graduate hours for successful completion.

Both graduate programs required the same application materials. For successful entry into the program, each teacher submitted a written statement of intent. In this document, applicants were asked to respond to four questions. First, the applicants were asked to explain why they were pursuing the degree and, second, what they hoped to accomplish through the program. In addition, the prospective graduate students were asked to describe personal and professional qualities that would help them be successful in the program. Finally, each applicant was asked to describe his/her educational philosophy. These four categories were used to organize the study findings.

\section{The sources of data}

For this study, copies of letters of intent for the two degree programs were provided by the university after all identifying information about the individuals was removed. Thus, demographic information about the respondents was not available. The researchers coded the letters in two groups -those seeking admission to the C\&I program and those seeking admission to the Administration program. The 52 applicants' statements of intent for the M.Ed. in C\&I formed the first set of data, and the 68 statements of intent for the M.Ed. in Ed.Ad. formed the second data set.

The M.Ed. in C\&I required students to complete a core group of classes focusing on curriculum and instruction and educational research. After completing the required core classes, students finished additional coursework in a specialization area such as Bilingual Education, English as a Second Language, or Special Education.

The M.Ed. in Ed.Ad. required students to complete a core group of classes focused on public school administration as well as educational research. Additionally, students were offered elective classes designed to prepare them to meet principal licensure requirements. Neither program required a thesis; however, both programs required a capstone project known as a professional paper. Letters of intent from each group were analyzed using a process by which key themes were identified.

\section{Data Analysis and Interpretation}

The data were coded on two levels. First, using content analysis techniques as conceptualized by Wolcott (2009), the statements of intent were coded for frequently used words and phrases 
that were then categorized into broad patterns and themes. The patterns and/or themes served to summarize the data and provided foundational information that could be used for cross case analysis as suggested by Miles and Huberman (1994) in their seminal work on the analysis of qualitative data.

Then, as the second level of analysis, the emergent themes were compared across the two categorical groups: curriculum/instruction and educational leadership. The researchers examined the statements for similarities and differences between the two career path groups in accordance with qualitative methodology. While there were many commonalities within and between the samples, there were also a number of distinctions across the sets. Hence, for richer description, we compared and contrasted the two groups of letters as unique cases by analyzing both within and across the cases as described by Yin (2009).

\section{Findings}

Letters of application from the two study participant groups contained a variety of reasons as to why that particular career path was chosen for Master's degree emphasis. From each set of data, interesting themes emerged. Teachers seeking the curriculum degree focused more on classroom performance indicators as suggested by the multiple uses of terms such as "developmentally appropriate, passion for learning, effective teaching, and learning environment”. Potential administrators, however, held a more campus level perspective as indicated by numerous references to terms such as "leadership, communication, data, and management”.

\section{Teachers Seeking Curriculum Degree}

Teachers applying for the curriculum degree indicated several reasons as to why they chose the strand on which to focus during their Master's degree coursework. Four broad themes which surfaced depicted a desire to: (1) remain current and on the "cutting edge" of available knowledge and skills, (2) further impact in areas beyond the classroom; to participate in the profession on a wider scope, (3) improve self; to learn and grow professionally, and (4) give back to the profession and the community.

\section{Curriculum - Reasons for Pursuing the Degree}

Teachers seeking the Master's degree in curriculum overwhelmingly indicated they sought to keep current regarding knowledge in their field. Whether the focus was general education, special education, English as a second language (ESL), or bilingual education, the teachers noted a Master's degree was essential if they were to "stay up to date on teaching methodology" and "maintain a higher and more effective level of instruction to my students".

In 40 letters of intent, teachers indicated the pursuit of a Master's degree would give them opportunities to delve deeper into the constructs of the instructional process as they noted they wished to "gain better knowledge of how to educate young children", "[gain] further knowledge of curriculum design" and "strengthen [my] skills and knowledge base”. Several letters espoused less lofty and seemingly more straightforward reasons for pursuit of the degree with statements such as, "I always planned on it”, “ [it will help me] better meet the 
needs of all students”, “want to pursue a doc degree”, and “I didn’t find a job”. Seven teachers did not indicate their reasons for pursuing the Master's degree.

Curriculum - Goals

Goals set by the C \& I teacher applicants predominately indicated a desire to impact educational stakeholders beyond the classroom. Teachers indicated they understood how they influenced the students within their classrooms each day; however, more was desired. For teachers who possessed only certification in general education, many sought to add additional certification in areas such as special education, ESL, or bilingual education. Others stated they would like to become "campus instructional leaders", "start [their] own school[s]", become a "college instructor of perspective [sic] elementary teachers", or become a "teacher trainer at a district, university, or educational service center." From their responses, it was apparent applicants understood the potential impact procurement of a master's degree could have on their careers.

Curriculum - Personal and Professional Qualities

Each applicant indicated those qualities they perceived would contribute to their success as a Master's student. A majority of candidates described qualities that attributed to their growth both personally and professionally. Possessing enthusiasm, perseverance, determination, and a passion for learning new techniques were frequently cited as applicable personal qualities illustrative of a lifelong learner. Other professional qualities that participants reported sharing with effective teacher leaders were, for example, “open-mindedness”, “relationship-builder”, “strong classroom teacher”, "strong work ethic”, “organized”, and “team-player”.

Curriculum - Perspectives on Education

While teacher applicants' perspectives on education were varied, they appeared to have one commonality: education is "a lifelong process and there is always something new that can be learned”; its impact knows no boundaries. Teacher applicants spoke of ways in which their Master's degree in curriculum might enhance their ability to give back to both the community they serve and the profession as a whole.

Many applicants stated that while "teaching is the most rewarding profession" and "teachers play an important role in society", it takes a "special person" to do it; they must be willing to "interact with others and learn something each day". Several applicants underscored the impact teachers have on the life of a child. Applicants also stated the need for "cooperation among all who deal with the child, parents and school personnel alike". As one candidate stated, "I know this program will offer me the tools and knowledge...so I may make an impact....while challenging and encouraging [my students] to view their education as a door to the future."-

\section{Teachers Seeking Administration Degree}

Teachers applying for the administration degree indicated several reasons as to why they chose that particular strand on which to focus during their Master's degree coursework. From qualitative analysis of 68 educational leadership letters of intent submitted, four broad themes 
surfaced indicating applicants for this degree desired to: (1) expand their sphere of influence, (2) utilize effective leadership skills to create a supportive school environment which valued all stakeholders, (3) model a strong work ethic, and (4) give back to the profession and the community.

\section{Administration - Reasons for Pursuing the Degree}

Teacher applicants seeking the Master's degree in educational administration overwhelmingly cited a desire to extend their sphere of influence as a major reason for seeking the degree. Applicants indicated a wish to impact the lives of all stakeholders, not just "their" students within personal classroom walls. As one candidate stated, "I would like to work hand in hand with fellow educators to ensure student success." Another noted, "As a teacher, I influence only those students I teach. As an administrator, I would have opportunities to influence all students in the school." Others articulated thoughts such as, "As an administrator, I can have a stronger and further reaching impact on the students and the community I serve," and "I have realized my strength in education extends beyond the classroom.” Applicants indicated pursuit of a Master's in educational administration was the first step in expanding their realm of influence. These results coincided with Adams' and Hambright's work (2004) in which respondents indicated the reasons for pursuing administration as a career was to initiate change and provide the necessary leadership to implement that change.

Administration - Goals

A majority of the education administration applicants stated enhancement and development of leadership skills as a goal. Realizing that effective leaders "facilitate educators and students alike down the roads of their education, stirring them to strive for what they do best," more than half of the candidates for this degree stated they aspired to become a school administrator. For instance, one teacher stated, "I want to be on the principal side for a change. It is time for a change.” Several teachers expressed concern about the current system and the desire to change it. A typical response, "The educational system is failing many of our students." Lastly, an applicant stated, "without the support of good administration, however, their efforts can be quickly thwarted."

Not all candidates, however, aspired to be campus administrators. Of those stating a definitive career goal, the list of other possibilities included other positions such as superintendents, curriculum specialists, facilitators of regional day schools, and college professors. One administrative applicant wrote, "I believe I can have a significant impact on educational content and methodology for a broad school system. My intent is to redefine the educational process by becoming an educational leader in the school system." Several candidates also indicated completion of the Master's degree was a prerequisite for the accomplishment of their "ultimate goal of obtaining a doctorate." Whatever their title, applicants indicated successful school administrators were those leaders who were "equipped with the necessary equitable manner.” 
Administration - Personal and Professional Qualities

Candidates pursuing a Master's in education administration perceived strong ethical leadership qualities to be indicative of future successes as educational leaders. Applicants pointed to personal attributes such as "driven...strong desire to learn...", "respectful of others”, "passionate”, "responsible...dependable...high moral code.” Professional qualities perceived as indicative of effective leaders included "good communicator", "innovative”, "motivating”, "team player", "good manager", and "problem solver". One applicant suggested both personal and professional traits were needed for success in the field because "commitment to the profession required [someone who was] detail-oriented, highly organized, and capable of working under strict deadlines.”

\section{Administration - Perspectives on Education}

When discussing perspectives about education, a common emergent theme among applicants was the desire to share expertise in a manner that would impact the profession in a positive manner. For some applicants, that involved doing all things possible to improve the lives of students. As one candidate stated, "I want to share research based materials that [would] add and enhance the lives of students..." Another shared she wanted to develop her "ability to assess students' academic skills...to determine strengths and weaknesses...to help overcome learning barriers."

For others, giving back to the profession involved motivating both teachers and students to strive for their potential best. One candidate noted she wanted to "inspire those I lead to achieve their greatest potential.” Other applicants offered similar statements when they asserted thoughts such as "I want to motivate teachers to utilize technology in the classroom"; "[I want] teachers to believe in a vision"; or "[I want] to empower teachers so they will be more productive." Finally, one student summed up the impact of motivation by stating; "If an educator is motivated, they provide the individual with the tools and knowledge they need to take part in today's world.”

\section{Similarities and Differences Between the Two Groups}

The most notable similarity between the two groups was the desire to keep learning about their profession and improve their craft. Words and phrases like "lifelong learning", "skills", and "effective" were common to both groups. A second overarching theme was the focus on students. Both groups had comments such as, "make a difference" and "influence to do their best" and a belief that all individuals have a desire and right to learn. Each group, therefore, saw the potential for improving both self and others as they pursued their new role and career path. Candidates pursuing Master's degrees in both C\&I and educational administration expertise realized their expanded realm of influence provided multiple opportunities for them to lead others by sharing knowledge and learn about themselves in the process.

While similarities were evident, so were differences between the two degree seeking candidate groups. One of the most notable differences was the desire for teachers in the curriculum and instruction Master's program to add additional teaching certifications such as English as a Second Language or Special Education while the administration Master's degree 
seekers sought to add only the principal certification. Perhaps C\&I candidates believed their marketability and credibility would be enhanced if they possessed qualifications for a multiplicity of positions. Or, perhaps C\&I candidates were looking to stay within their school as a curriculum specialist or work as a curriculum director at the district level. To be effective in positions such as these, additional certification could provide knowledge of appropriate instructional techniques for students all along the academic spectrum including, for example, gifted students, English language learners, and/or students with special needs. The educational administration degree seekers, on the other hand, may perceive their career advancement requires only one or two additional moves (from assistant principal to principal for example). Therefore, the administration certification alone would suffice.

Additionally, reasons for pursuing the two degrees varied widely, thus providing some insight into the candidates' thoughts, expectations or wishes for the future. On a whole, C\&I Master's candidates wanted to become more skilled as teachers in order to better serve their students. One teacher indicated she "hoped to grow professionally". Thiat was the tone of many of the letters. Conversely, the administration degree seekers, it appeared, were looking to make change. Many stated they endeavored to do this by moving up into administrative roles within their district.

\section{Final Thoughts}

This study explored Master's degree candidates’ reasons for pursuing an advanced degree in either C\&I or educational administration. Results indicated those who chose to pursue a graduate degree in C\&I, by far, wished to both enhance their knowledge base and improve the effectiveness of their craft. Such reasoning would seem to validate Cornett's (1990) contention that each teacher develops basic personal practical theories which both guide and direct his/her view of self as a professional. Outcomes of this type also align with Chapman, Al-Barwani, Mawali, and Green's (2012) assertion that an initial commitment to teaching as a career constitutes a lens by which teachers view all career advancement opportunities.

On the other hand, students pursuing a Master's degree in administration reported they desired to further develop (1) skill sets which would help them become better communicators and (2) leadership qualities which would enable them to impact a greater number of educational stakeholders than would have been possible if they had chosen to remain in a single classroom. This supports the argument put forth by Blase and Kirby (2009) that the school principal affects virtually all aspects of the educational process. Both participating Master degree candidate groups, therefore, shared a common goal-to continue impacting students in a positive way. The divergence was the path chosen to meet that objective.

Ibarra's (1999) notion of provisional selves is a useful lens through which to examine the candidates' decisions to pursue either the curriculum or the administration path. The letters of intent depict, for example, different sets of personal and professional qualities that impact candidates' choice, described by Ibarra as personal factors. Situational factors that appear to impact career decisions were especially salient in the candidates' perceptions of how relationships with co-workers and students would differ based on their chosen career path. As 
such, both personal and social factors emerge from these data and the study suggests that both play a significant role in the career decision.

These findings contribute to the field's understanding of motivating factors guiding Master degree in Education candidates' selection of either C\&I or educational leadership as a career focus. Graduate C\&I candidates tended to focus on enhancing their individual performance as a teacher or teacher leader while applicants in educational leadership wished to pursue the principalship. To that end, these findings may be of interest to universities, colleges, and other entities that prepare and/or hire administrators or teacher leaders. Results may also be of interest to practicing teachers interested in pursuing a Master's degree. Data may help potential graduate students examine and reflect upon their career goals in an effort to determine the program that aligns with their needs.

\section{References}

Adams, K., \& Hambright, G. (2004). Encouraged or discouraged? Women teacher leaders becoming principals. The Clearinghouse, 77(5), 209-211. http://dx.doi.org/10.3200/TCHS.77.5.209-212

Armstrong, D. (2009). Administrative passages: Navigating the transition from teacher to assistant principal. New York, NY: Springer.

Blase, J., \& Kirby, P. (2009). Bringing out the best in teachers: What effective principals do. ( $3^{\text {rd }}$ edition). Thousand Oaks, CA: Corwin Press.

Chapman, D., Al-Barwani, T., Mawali, F., \& Green, E. Ambivalent journey: Teacher career paths in Oman. International Review of Education 58(3), 387-403. http://dx.doi.org/10.1007/s11159-012-9293-5

Cornett, J. W. (1990). Teacher thinking about curriculum and instruction: A case study of a secondary social studies teacher. Theory \& Research in Social Education, 18(3), 248-273. http://dx.doi.org/10.1080/00933104.1990.10505617

Danielson, C. (2006). Teacher leadership that strengthens professional practice. Alexandria, VA: Association for Supervision and Curriculum Development.

Donaldson, G. (2007). What teachers bring to leadership. In Uncovering teacher leadership Ackerman, R. H. \& Mackenzie, S. V. (eds.) Thousand Oaks, CA: Corwin Press.

Donaldson, G., Marnik, G., Mackensie, S., \& Ackerman, S. (2009). What makes or breaks a principal. Educational Leadership, 67(2), 8-14.

Howley, A., Solange, A., \& Perry, J. (2005). The pain outweighs the gain: Why teachers don’t become principals. Teachers College Record, 107(4), 757-782.

Ibarra, H. (1999). Provisional selves: Experimenting with image and identity in professional adaptation. Administrative Science Quarterly, 44, 764-791. http://dx.doi.org/10.2307/2667055

Lieberman, A., \& Miller, L. (2004). Teacher Leadership. San Francisco: Jossey Bass. 
Marshall, C., \& Kasten, K. (1994). The administrative career: A casebook on entry, equity, and endurance. Thousand Oaks, CA: Corwin Press.

Miles, M. B., \& Huberman, A. M. (1994). Qualitative data analysis: An Expanded Sourcebook. ( $2^{\text {nd }}$ ed.). Thousand Oaks, CA: Sage.

Phelps, P. (2008). Helping teachers become leaders. The Clearinghouse, 81(3), 119-122. http://dx.doi.org/10.3200/TCHS.81.3.119-122

Schmerler, G. (2009). Teacher leaders: Transforming schools from the inside. (ed.) Bank Street College Occasional Paper Series \#23. http://www.bankstreet.edu/gs/op23article1

Wolcott, H. (2009). Writing up qualitative research ( $3^{\text {rd }}$ ed.). Thousand Oaks: Sage.

Yin, R. (2009). Case study research: Design and methods. 4th Edition. Los Angeles: Sage Publications, Inc. 